\title{
Adults with type 1 diabetes eat a high-fat atherogenic diet that is associated with coronary artery calcium
}

\author{
J. K. Snell-Bergeon - C. Chartier-Logan • \\ D. M. Maahs • L. G. Ogden • J. E. Hokanson • \\ G. L. Kinney • R. H. Eckel • J. Ehrlich • M. Rewers
}

Received: 18 November 2008 / Accepted: 14 January 2009/Published online: 14 February 2009

(C) Springer-Verlag 2009

\begin{abstract}
Aims/hypothesis Coronary heart disease is the leading cause of mortality among people with type 1 diabetes. Diet is an important lifestyle factor that relates to risk of CHD. The aim of this study was to examine how diet and adherence to dietary guidelines differ between adults with and without type 1 diabetes, and their correlation with CHD risk factors and coronary artery calcium (CAC).

Methods The study involved 571 people with type 1 diabetes and 696 controls, aged 19 to 56 years, who were asymptomatic for CHD. CAC was measured by electron-beam computed tomography.

Results Compared with the controls, adults with type 1 diabetes reported a diet higher in fat, saturated fat and protein but lower in carbohydrates. Fewer than half of those with type 1 diabetes met dietary guidelines for fat and carbohydrate intake, and only $16 \%$ restricted saturated fat to less than $10 \%$ of daily energy intake. Adults with type 1 diabetes were significantly less likely to meet dietary guidelines than controls. Fat and saturated fat intakes were positively correlated, but carbohydrate intake was negatively correlated
\end{abstract}

J. K. Snell-Bergeon $(\bowtie) \cdot$ C. Chartier-Logan • D. M. Maahs •

G. L. Kinney $\cdot$ M. Rewers

Barbara Davis Center for Childhood Diabetes,

University of Colorado Denver,

P.O. Box 6511, Mail Stop A-140,

Aurora, CO 80045, USA

e-mail: Janet.Snell-Bergeon@ucdenver.edu

L. G. Ogden · J. E. Hokanson

Colorado School of Public Health,

University of Colorado Denver,

Aurora, CO, USA

R. H. Eckel · J. Ehrlich

Department of Medicine, University of Colorado Denver,

Aurora, CO, USA with CHD risk factors and $\mathrm{HbA}_{1 \mathrm{c}}$. A high-fat diet and higher intake of protein were associated with greater odds of CAC, while higher carbohydrate intake was associated with reduced odds of CAC.

Conclusions/interpretation Adults with type 1 diabetes reported consuming higher than recommended levels of fat and saturated fat. High fat intake was associated with increased CHD risk factors, worse glycaemic control and CAC. An atherogenic diet may contribute to the risk of CHD in adults with type 1 diabetes.

Keywords Carbohydrate intake - Coronary heart disease . Dietary intake $\cdot$ Fat intake $\cdot$ Type 1 diabetes mellitus

$\begin{array}{ll}\text { Abbreviations } \\ \text { ADA } & \text { American Diabetes Association } \\ \text { AHA } & \text { American Heart Association } \\ \text { CAC } & \text { Coronary artery calcium } \\ \text { CT } & \text { Computed tomography } \\ \text { DBP } & \text { Diastolic blood pressure } \\ \text { DRI } & \text { Dietary reference intake } \\ \text { EGDR } & \text { Estimated glucose disposal rate } \\ \text { GI } & \text { Glycaemic index } \\ \text { IAF } & \text { Intra-abdominal fat } \\ \text { IOM } & \text { Institute of Medicine } \\ \text { SBP } & \text { Systolic blood pressure }\end{array}$

\section{Introduction}

Coronary heart disease has been the leading cause of death in the USA for almost 80 years [1]. People with type 1 diabetes are at increased risk for developing CHD, with CHD mortality rates among adults with diabetes two to four 
times higher than the rates for adults without diabetes [2]. While most CHD mortality among adults can be attributed to type 1 diabetes [3], little is known about how well adults in the USA with type 1 diabetes meet dietary guidelines, and the influence of dietary intake on CHD risk in type 1 diabetes is not fully understood. The American Heart Association (AHA) has recognised that diet and lifestyle are important modifiable factors influencing CHD risk and that they are critical components of CHD prevention efforts [4].

Guidelines for medical nutrition therapy have been published by the American Diabetes Association (ADA) for patients with diabetes [5]. The dietary goals for patients with type 1 diabetes are largely in agreement with the dietary guidelines from the Institute of Medicine (IOM), which apply to healthy adults [6]. These include avoiding a low-carbohydrate diet and consuming: $45-65 \%$ of total energy in the form of carbohydrate; $10-35 \%$ of total energy in the form of protein; and 20-35\% of total energy in the form of fat. For patients with diabetes, both the ADA and the AHA [7] recommend limiting saturated fat to less than $7 \%$ of total energy intake, while the AHA recommends limiting saturated fat to less than $10 \%$ of total energy in the population at large. Among patients with kidney disease, protein should be limited to $0.8 \mathrm{~g} / \mathrm{kg}$ to prevent nephropathy [8]. As achieving glycaemic control $\left(\mathrm{HbA}_{1 \mathrm{c}}<7 \%\right)$ is an important ADA goal for patients with type 1 diabetes, the need to balance sufficient carbohydrate intake with the avoidance of postprandial hyperglycaemia is important and can potentially be addressed by taking into account the glycaemic index (GI) of carbohydrates in the diet [5].

A recent report from the SEARCH for Diabetes in Youth study found that adherence to dietary guidelines was poor among children and adolescents with type 1 diabetes [9]. The Norwegian Childhood Diabetes and Quality Project found that children and adolescents with type 1 diabetes had a high frequency of atherogenic risk factors [10], a high intake of energy from saturated fat and a low intake of fibre [11]. Another study in adolescents found that those with type 1 diabetes were heavier, ate more saturated fat and ate fewer portions of fruit and vegetables compared with those without diabetes [12].

Studies of dietary intake among adults with type 1 diabetes are sparse. The Diabetes and Nutrition Complications Trial in Spain found that adherence to ADA recommendations among adults with type 1 diabetes was low for fat and carbohydrate, although fat consumption was not associated with the incidence of diabetes complications [13]. On the other hand, an Australian study reported lower intakes of fat and saturated fat among adults with type 1 diabetes compared with non-diabetic controls, and no association between dietary intake and glycaemic control in participants with type 1 diabetes [8].
CHD is a chronic disease that develops over the course of decades, beginning as early as the teen years and progressing from fatty streaks to raised lesions and then complex lesions [14]. The detection of atherosclerosis in the preclinical stages is critical to furthering our understanding of risk factors that affect the early development and progression of disease. Coronary artery calcium (CAC) detected by electron-beam computed tomography $(\mathrm{CT})$ is a proxy measure for overall plaque burden [15-17], and the presence of CAC is a strong predictor of CHD events $[18,19]$.

The purpose of this study was to compare the dietary habits of adults with type 1 diabetes with those of adults without diabetes and to examine the association between diet, CHD risk factors and subclinical atherosclerosis.

\section{Methods}

Study participants The data presented in this report were collected as part of the baseline examination of the Coronary Artery Calcification in Type 1 Diabetes (CACTI) study. The study enrolled 1,416 individuals between 19 and 56 years of age, with no known history of CHD: 652 participants with type 1 diabetes and 764 control participants without diabetes. Participants with type 1 diabetes had long-standing disease (mean duration 23 years, range 4-52 years), were insulin dependent within 1 year of diagnosis, and were diagnosed prior to age 30 years or had positive antibodies or a clinical course consistent with type 1 diabetes.

Dietary intake Study participants who completed the baseline screening visit were asked to fill out a validated [20] selfadministered food-frequency questionnaire (Harvard, 1988); 1306 study participants completed the questionnaire. As per the guidelines suggested by Willett [21] for excluding individuals with implausible reported energy intake, 40 participants were excluded as they reported energy intake that was either very low $(<2.09 \mathrm{MJ}$ [500 kcal] per day for women or $<3.35 \mathrm{MJ}$ [800 kcal] per day for men), or very high $(\geq 14.64 \mathrm{MJ}[3,500 \mathrm{kcal}]$ for women, $\geq 16.74 \mathrm{MJ}$ [4,000 kcal] or higher for men), leaving 571 participants with type 1 diabetes and 696 controls in this analysis.

Cardiovascular risk factors Participants completed a baseline examination between March 2000 and April 2002. Anthropometric measurements were obtained, including height, weight, minimum waist circumference (measured at the smallest point between the tenth rib and the iliac crest, over bare skin, in duplicate), and hip circumference (measured at the maximum circumference of the buttocks, in duplicate). Body mass index was calculated in $\mathrm{kg} / \mathrm{m}^{2}$. Resting systolic blood pressure (SBP) and fifth-phase diastolic blood pressure (DBP) were measured three times 
while the patients were seated, following a 5 min rest, and the second and third measurements were averaged. Hypertension was defined as a blood pressure $\geq 140 / 90 \mathrm{mmHg}$, or participant receiving current antihypertensive treatment. Participants completed standardised questionnaires that enquired about medical history, Rose angina, current medication, insulin doses, physical activity, alcohol and tobacco use and family medical history.

Following a $12 \mathrm{~h}$ fast, participants came to the clinic in the morning for blood collection, as previously described. Lipids (total cholesterol, HDL-cholesterol, LDL-cholesterol and triacylglycerols), fasting glucose and $\mathrm{HbA}_{1 \mathrm{c}}$ were measured, and non-HDL-cholesterol (total cholesterol minus HDLcholesterol) was calculated. Albumin excretion rate was calculated from urinary albumin measured in two timed overnight urine samples, and the results from the two nights were averaged. Abdominal fat at the lumbar 4-5 region was quantified by CT, and volumes of intra-abdominal fat (IAF) and subcutaneous fat were determined. Estimated glucose disposal rate (EGDR) was calculated according to the formula published by the Pittsburgh Epidemiology of Diabetes Complications Study and derived from euglycaemic hyperinsulinaemic clamps performed in 24 patients with type 1 diabetes: $\mathrm{EGDR}=24.31-12.22 \times($ waist/hip ratio) $-3.29 \times($ hypertension $)-0.568 \times\left(\mathrm{HbA}_{1 \mathrm{c}}\right)$ [22].

CAC measurement by electron-beam CT Two sets of highresolution non-contrast contiguous $3 \mathrm{~mm}$ tomographic images were acquired at $0.1 \mathrm{~s}$ exposure on an Imatron C-150XLP electron-beam CT scanner (Imatron, San Francisco, CA, USA) as previously described [23]. The two sets of scans were acquired within $5 \mathrm{~min}$, and $\mathrm{CAC}$ scores were averaged.

Statistical analysis Variables were examined for normality, and non-normally distributed variables (triacylglycerols, visceral fat and subcutaneous fat) were $\log$ transformed. Differences in risk factors between men and women with type 1 diabetes and without diabetes were examined using a Student's $t$ test. A $\chi^{2}$ test for goodness of fit was used to determine if categorical risk factors differed between patients with type 1 diabetes and non-diabetic participants.

Correlations between dietary macronutrients and micronutrients and CHD risk factors were examined using Pearson correlation coefficients. Logistic regression analysis was used to examine the relationship between presence of CAC ( 0 vs any CAC) and dietary macronutrients and micronutrients.

The association of each dietary factor with the presence of $\mathrm{CAC}$ was examined in a logistic regression model adjusted for age, sex, total daily energy intake and diabetes status (Model 1); the potential mediators of the relationship between dietary factors and presence of CAC were then examined by individually adding them to Model 1 .
Informed consent All study participants provided informed consent and the study protocol was approved by the Colorado Multiple Institutional Review Board.

\section{Results}

Characteristics of study participants are shown in Table 1 . Both male and female study participants with type 1 diabetes were significantly younger than participants without diabetes. Only $18 \%$ of men and $22 \%$ of women with type 1 diabetes met the ADA's goal of $\mathrm{HbA}_{1 \mathrm{c}}<7 \%$. Men with type 1 diabetes had less IAF, a smaller average waist circumference, lower total and LDL-cholesterol, lower triacylglycerol and higher HDL-cholesterol than men without diabetes. Similarly, women with type 1 diabetes had less IAF, lower total cholesterol and LDL-cholesterol, lower triacylglycerol and higher HDL-cholesterol than women without diabetes. Physical activity levels did not differ by diabetes status among men or women, but AER and CAC were significantly increased in participants with type 1 diabetes compared with those without diabetes.

Daily energy intake (kJ/kg body weight) did not differ in men by diabetes status, but women without diabetes reported a higher daily intake of energy $(\mathrm{kJ} / \mathrm{kg}$ body weight) than women with type 1 diabetes. However, both men and women with type 1 diabetes reported consuming less of their daily energy intake as carbohydrate, and more as fat and protein than non-diabetic individuals. In addition, saturated fat intake as a percentage of daily energy intake was significantly higher in both men and women with type 1 diabetes than in men and women without diabetes. Glycaemic index, the ratio of the influence of a food on blood sugar levels $(2 \mathrm{~h}$ glucose area under the curve) compared with glucose and multiplied by 100 , was similar in all groups. However, glycaemic load, which is the carbohydrate content in $\mathrm{g}$ multiplied by the GI and then divided by 100 , was significantly lower in men and women with type 1 diabetes compared with control men and women.

Figure 1 shows adherence to dietary guidelines (ADA, AHA and Dietary Reference Intake [DRI]) in the cohort, by diabetes and sex. Significantly fewer individuals with type 1 diabetes met the DRI goal for total fat intake (20-35\% of daily intake) than controls, and fewer people with type 1 diabetes met the goal for saturated fat intake of $<10 \%$ of daily energy intake. Fewer adults with type 1 diabetes than controls met the goal of obtaining $45-65 \%$ of daily energy intake from carbohydrate, but nearly all participants met the recommended goals for protein intake $(10-35 \%$ of daily intake). Adherence to guidelines for intake of folate, vitamin E, calcium and fibre did not differ by diabetes status. All women met the daily recommended intake of vitamin $\mathrm{C}$, while control men had significantly lower 
adherence to vitamin $\mathrm{C}$ guidelines than men with type 1 diabetes. Fewer than half of study participants met calcium guidelines, with calcium intake being lowest among control men and significantly lower than in men with type 1 diabetes. Fibre intake did not differ by diabetes status, but only $6 \%$ of men in both groups met fibre guidelines, while $30 \%$ of women with type 1 diabetes and $31 \%$ of women without diabetes met the fibre guidelines.

We examined whether the dietary composition was correlated with CHD risk factors, including total cholesterol, LDL- and HDL-cholesterol, triacylglycerol, non-HDLcholesterol, apolipoprotein $\mathrm{B}, \mathrm{HbA}_{1 \mathrm{c}}$, BMI, IAF volume, waist circumference and EGDR. As shown in Table 2, the percentage of energy intake from fat, the percentage of energy from saturated fat, and the percentage of energy from monounsaturated fatty acids were all significantly positively correlated with total cholesterol and LDL-cholesterol, nonHDL-cholesterol, apolipoprotein $\mathrm{B}, \mathrm{HbA}_{1 \mathrm{c}}$, BMI, IAF, waist circumference and DBP, and negatively correlated with EGDR. The percentage of energy from trans fats and the percentage of energy from polyunsaturated fatty acids were also significantly positively correlated with LDLcholesterol, non-HDL-cholesterol, apolipoprotein B, BMI, IAF, waist circumference and DBP, and negatively correlated with EGDR. A higher average dietary glycaemic index was associated with lower HDL-cholesterol and EGDR and higher triacylglycerol, non-HDL-cholesterol, apolipoprotein B, IAF, SBP and DBP. Conversely, increased carbohydrate intake was significantly negatively correlated with total cholesterol, LDL- and HDL-cholesterol, non-HDL-cholesterol, apolipoprotein $\mathrm{B}, \mathrm{HbA}_{1 \mathrm{c}}$, BMI, IAF, waist circumference and DBP, and significantly positively associated with EGDR.

Table 1 Characteristics of study participants by sex and diabetes status

\begin{tabular}{|c|c|c|c|c|}
\hline \multirow[t]{2}{*}{ Characteristic } & \multicolumn{2}{|l|}{ Men } & \multicolumn{2}{|l|}{ Women } \\
\hline & Type 1 diabetes $(n=250)$ & Control $(n=347)$ & Type 1 diabetes $(n=321)$ & Control $(n=349)$ \\
\hline Age (years) & $38 \pm 9^{*}$ & $40 \pm 9$ & $36 \pm 9^{*}$ & $39 \pm 9$ \\
\hline $\mathrm{HbA}_{1 \mathrm{c}}(\%)$ & $8.0 \pm 1.2 * * *$ & $5.6 \pm 0.4$ & $8.0 \pm 1.3 * * *$ & $5.4 \pm 0.4$ \\
\hline Met goal of $\mathrm{HbA}_{1 \mathrm{c}}<7 \%(\%)$ & 18 & N/A & 22 & N/A \\
\hline Duration (years) & $24 \pm 9$ & N/A & $23 \pm 9$ & N/A \\
\hline $\operatorname{IAF}\left(\mathrm{cm}^{2}\right)$ & $38(3-183)^{* * *}$ & $54(4-206)$ & $26(7-133)^{*}$ & $29(7-246)$ \\
\hline BMI $\left(\mathrm{kg} / \mathrm{m}^{2}\right)$ & $26.6 \pm 3.9$ & $27.2 \pm 4.1$ & $25.9 \pm 4.7$ & $25 \pm 4$ \\
\hline Waist circumference $(\mathrm{cm})$ & $90.9 \pm 11.1^{*}$ & $93.2 \pm 12.1$ & $80.6 \pm 11.9$ & $78.8 \pm 12.9$ \\
\hline Cholesterol (mmol/l) & $4.52 \pm 0.91 * * *$ & $5.12 \pm 1.12$ & $4.55 \pm 0.85^{* * *}$ & $4.79 \pm 0.87$ \\
\hline HDL-cholesterol (mmol/1) & $1.31 \pm 0.35^{* * *}$ & $1.12 \pm 0.28$ & $1.57 \pm 0.44^{*}$ & $1.50 \pm 0.36$ \\
\hline Non-HDL-cholesterol (mmol/1) & $3.2 \pm 0.9 * * *$ & $4.0 \pm 1.0$ & $3.0 \pm 0.8 * * *$ & $3.3 \pm 0.9$ \\
\hline \multicolumn{5}{|l|}{ LDL-cholesterol (mmol/l) } \\
\hline All $(n=1,267)$ & $2.71 \pm 0.77 * * *$ & $3.19 \pm 0.90$ & $2.53 \pm 0.74 * * *$ & $2.77 \pm 0.75$ \\
\hline No lipid therapy $(n=1,132)$ & $2.73 \pm 0.77 * * *$ & $3.17 \pm 0.89$ & $2.51 \pm 0.74 * * *$ & $2.77 \pm 0.76$ \\
\hline Apolipoprotein B (g/l) & $0.95 \pm 0.24^{* * *}$ & $1.13 \pm 0.28$ & $0.89 \pm 0.23 * * *$ & $0.95 \pm 0.24$ \\
\hline Triacylglycerol (mmol/l) & $0.9(0.7-1.3)^{* * *}$ & $1.4(1.0-2.0)$ & $0.9(0.7-1.2)^{* * *}$ & $1.0(0.8-1.4)$ \\
\hline Physical activity (kJ/week) & $7,517(3,165-14,118)$ & $6,986(3,048-12,861)$ & $5,020(1,938-10,862)$ & $6,232(2,859-11,255)$ \\
\hline $\mathrm{EGDR}^{\mathrm{a}}$ & $7.4 \pm 2.2 * * *$ & $9.6 \pm 1.7$ & $9.1 \pm 2.1 * * *$ & $11.5 \pm 1.5$ \\
\hline $\operatorname{AER}(\mu \mathrm{g} / \mathrm{min})$ & $7.4(4.7-24.6)^{* * *}$ & $4.4(3.4-6.4)$ & $5.5(3.7-11.6)^{* * *}$ & $3.9(2.8-5.4)$ \\
\hline $\begin{array}{l}\text { Energy intake } \\
{\text { (kJ day }{ }^{-1} \mathrm{~kg} \text { body weight }}^{-1}\end{array}$ & $98.8 \pm 35.3$ & $97.6 \pm 34.5$ & $99.3 \pm 39.3^{*}$ & $105.8 \pm 39.5$ \\
\hline $\begin{array}{l}\text { Carbohydrate } \\
\text { (\% daily energy intake) }\end{array}$ & $44 \pm 9 * * *($ range $15-68)$ & $47 \pm 9($ range $9-78)$ & $45.9 \pm 9.0^{* * *}($ range $23-78)$ & $48.5 \pm 9.2($ range $21-79)$ \\
\hline Fat (\% daily energy intake) & $36.0 \pm 7.4 * * *($ range $17-67)$ & $33.3 \pm 6.8($ range $10-64)$ & $34.7 \pm 7.1 * * *$ (range 13-57) & $32.3 \pm 6.9($ range $11-53)$ \\
\hline Protein (\% daily energy intake) & $18.8 \pm 3.5^{*}($ range $10-35)$ & $18.0 \pm 4.0($ range $5-37)$ & $19.6 \pm 3.8 *$ (range $9-36)$ & $18.9 \pm 3.8($ range $9-39)$ \\
\hline $\begin{array}{l}\text { Saturated fat } \\
(\% \text { daily energy intake })\end{array}$ & $12.9 \pm 3.1 * * *$ & $11.8 \pm 2.8$ & $12.6 \pm 3.2 * * *$ & $11.6 \pm 3.0$ \\
\hline $\begin{array}{l}\text { Trans fat } \\
(\% \text { daily energy intake) }\end{array}$ & $0.90 \pm 0.32$ & $0.88 \pm 0.30$ & $0.85 \pm 0.30^{*}$ & $0.79 \pm 0.31$ \\
\hline Glycaemic index & $54.4 \pm 4.0$ & $54.9 \pm 4.1$ & $52.8 \pm 4.4$ & $53.4 \pm 4.1$ \\
\hline Glycaemic load & $117.2 \pm 46.7^{*}$ & $129.1 \pm 54.0$ & $99.2 \pm 45.1^{*}$ & $107.7 \pm 44.0$ \\
\hline CAC (Agatston units) & $84.7 \pm 302.4^{*}$ & $30.5 \pm 148.8$ & $45.3 \pm 186.1^{* * *}$ & $2.6 \pm 17.4$ \\
\hline
\end{tabular}

Data are means \pm SD or median (interquartile range)

${ }^{a}$ EGDR was calculated according to the formula published by the Pittsburgh Epidemiology of Diabetes Complications (EDC) Study and derived from euglycaemic hyperinsulinaemic clamps performed in 24 patients with type 1 diabetes (see the Methods section)

${ }^{*} p<0.05, * * * p<0.001$ for difference by diabetes status within each sex 

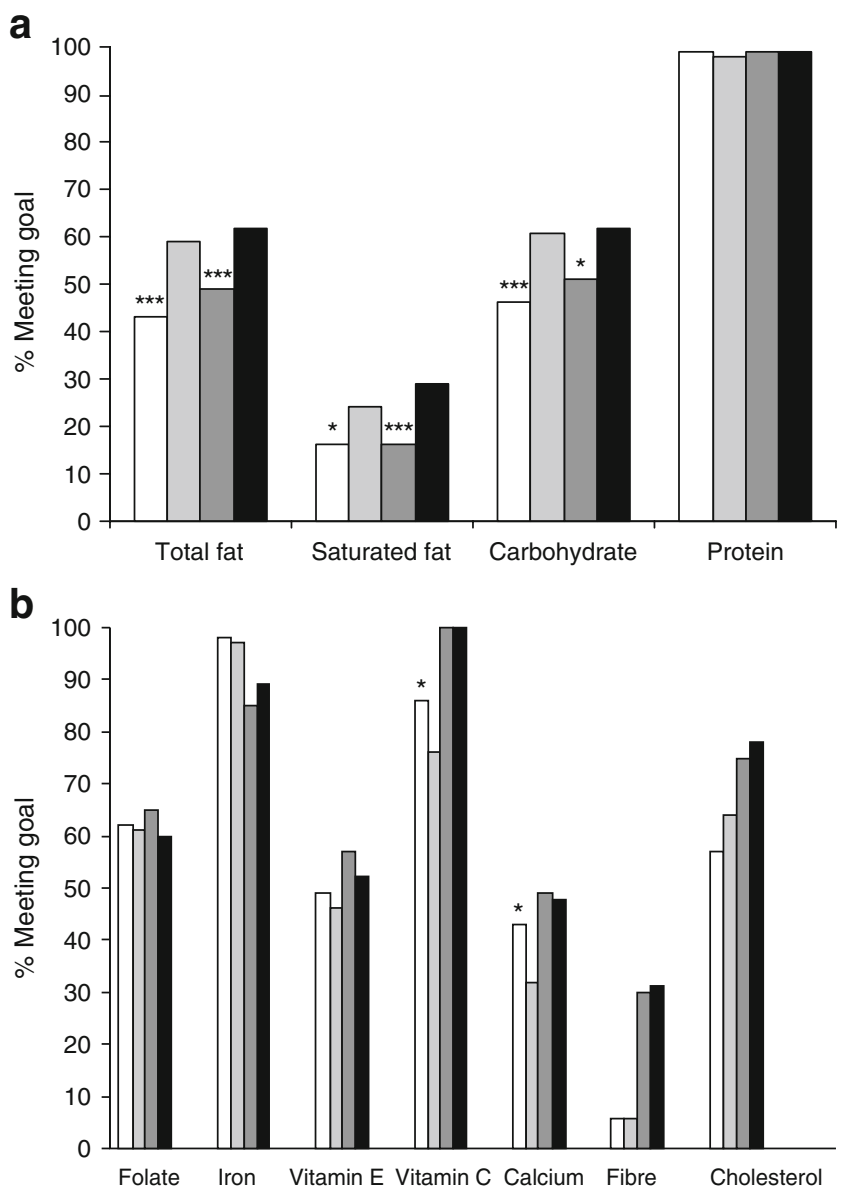

Fig. 1 Percentage of study participants meeting dietary goals for (a) macronutrients and (b) micronutrients by sex and diabetes status (white bars: men with type 1 diabetes; light grey bars: non-diabetic men; dark grey bars: women with type 1 diabetes; black bars: nondiabetic women). The macronutrient goals were, as a proportion of daily energy intake: total fat $=20-35 \%$ (ADA, DRI); saturated fat $<10 \%$ (AHA); carbohydrate $=45-65 \%$ (ADA, DRI); protein $=10-35 \%$ (ADA, DRI). The daily micronutrient goals were: folate $400 \mathrm{mg}$; iron $6 \mathrm{mg}$ for men, $8.1 \mathrm{mg}$ for women; vitamin E $15 \mathrm{mg}$, vitamin C $90 \mathrm{mg}$ for men, $75 \mathrm{mg}$ for women; calcium $1 \mathrm{~g}$ for those aged 19-50 years, $1.2 \mathrm{~g}$ for those aged 51-70 years; fibre $29.3 \mathrm{~g}$ for men, $19.2 \mathrm{~g}$ for women; cholesterol $<300 \mathrm{mg}$ (all from DRI). ${ }^{*} p<0.05$, $* * * p<0.001$ for difference by diabetes status within sex

Univariate associations between variables of interest and CAC were explored (Table 3), and all covariates were significantly associated with the presence of CAC except for intake of protein and glycaemic index. The relationship between dietary composition and presence of CAC was then examined in logistic regression models, shown in Table 4 . Model 1 was adjusted for age, sex, total energy intake per day and diabetes status, and interaction terms for diabetes status and each dietary variable were included but were nonsignificant $(p>0.10)$ and were therefore omitted from the analyses. A high-fat diet ( $>35 \%$ fat), saturated fat as a high percentage of energy intake, and protein intake as a high percentage of energy intake were associated with increased odds of CAC when adjusted for Model 1, and when further adjusted for triacylglycerol and $\mathrm{HbA}_{1 \mathrm{c}}$. Protein intake remained associated with the presence of $\mathrm{CAC}$ when adjustment was made for HDL- and LDL-cholesterol, hypertension, physical activity and EGDR, and a high-fat diet remained significantly associated with $\mathrm{CAC}$ when adjusted for $\mathrm{HbA}_{1 \mathrm{c}}$ and AER. The percentage of energy from carbohydrate was associated with decreased odds of CAC when adjusted for Model 1 (age, sex, total energy intake per day and diabetes status), and remained significantly associated with reduced odds of CAC when further adjusted for lipids, hypertension, physical activity, $\mathrm{HbA}_{1 \mathrm{c}}$ and AER. Associations between a high-fat diet, intakes of saturated fat, carbohydrate and protein and CAC were all attenuated when adjustment was made for BMI. Glycaemic index was not associated with CAC in any of the models. A fully adjusted model (excluding EGDR and non-HDL cholesterol as these variables are a linear combination of other variables) revealed that the relationships between dietary variables and CAC were not significant when adjusted for all other variables of interest.

Finally, in order to explore inter-relationships between dietary components, a forward selection logistic regression model was fitted, with age, diabetes status, high-fat diet, protein intake, carbohydrate intake and glycaemic index forced into the model (Table 5). Additional variables that were entered in the model were triacylglycerol, BMI and EGDR, and an interaction term for protein intake and diabetes status. Protein intake was significantly associated with presence of CAC only among participants with type 1 diabetes when adjusted for other dietary variables.

\section{Discussion}

In the present study we found that adults with long-standing type 1 diabetes consume a diet that differs significantly from their non-diabetic controls, who were recruited from spouses and friends of participants with type 1 diabetes as well as from the community, despite dietary guidelines on intake of dietary macronutrients being the same for both groups. Adults with type 1 diabetes reported eating more fat and saturated fat and less carbohydrate than the participants without diabetes. In particular, few men and women with type 1 diabetes met the guidelines to restrict saturated fat intake to less than $10 \%$ of daily energy intake, and almost none met the more stringent guideline for saturated fat being less than $7 \%$ of daily energy intake, which applies to people with elevated LDL-cholesterol, CHD or CHD-risk equivalent. Fewer than half of men and women with type 1 diabetes met the recommendations for total fat intake (20-35\% of daily energy intake). Male and female controls had significantly higher adherence to the guidelines from the AHA and IOM, which apply to adults with and 
Table 2 Pearson partial correlation coefficients for proportion of dietary intake of fats and carbohydrates, adjusted for age, sex, energy intake per day and type 1 diabetes

\begin{tabular}{|c|c|c|c|c|c|c|c|c|}
\hline Variable & $\%$ Fat & $\%$ Saturated fat & $\%$ Trans fat & $\%$ MUFA & $\%$ PUFA & Glycaemic index & $\% \mathrm{CHO}$ & $\%$ Protein \\
\hline Total cholesterol & $0.14 * * *$ & $0.12 * * *$ & $0.11 * * *$ & $0.14 * * *$ & 0.05 & 0.04 & $-0.14 * * *$ & 0.01 \\
\hline LDL-cholesterol & $0.15^{* * *}$ & $0.14 * * *$ & $0.12 * * *$ & $0.16^{* * *}$ & $0.06^{*}$ & 0.03 & $-0.13 * * *$ & 0.03 \\
\hline HDL-cholesterol & -0.02 & -0.02 & -0.04 & -0.03 & -0.01 & $-0.06^{*}$ & $-0.08 *$ & -0.02 \\
\hline Non-HDL-cholesterol & $0.15 * * *$ & $0.14 * * *$ & $0.13 * * *$ & $0.15^{* * *}$ & 0.05 & $0.07 *$ & $-0.11 * * *$ & 0.01 \\
\hline Apolipoprotein B & $0.13 * * *$ & $0.11 * * *$ & $0.09 * * *$ & $0.13 * * *$ & 0.05 & $0.07 *$ & $-0.09 *$ & 0.02 \\
\hline Triacylglycerol & 0.008 & 0.007 & 0.05 & 0.01 & -0.02 & $0.11^{* * *}$ & 0.02 & -0.02 \\
\hline SBP & 0.04 & $0.06^{*}$ & $0.06^{*}$ & 0.05 & -0.04 & $0.11 * * *$ & -0.03 & -0.05 \\
\hline DBP & $0.08 *$ & $0.09 *$ & $0.09 *$ & $0.08 *$ & -0.01 & $0.10 * * *$ & $-0.06^{*}$ & -0.01 \\
\hline BMI & $0.18^{* * *}$ & $0.16^{* * *}$ & $0.14 * * *$ & $0.18 * * *$ & $0.06^{*}$ & 0.05 & $-0.15^{* * *}$ & $0.09 *$ \\
\hline IAF & $0.19 * * *$ & $0.17 * * *$ & $0.16^{* * *}$ & $0.20 * * *$ & $0.08 *$ & $0.10 * * *$ & $-0.14 * * *$ & 0.01 \\
\hline Waist circumference & $0.20 * * *$ & $0.18 * * *$ & $0.15^{* * *}$ & $0.19 * * *$ & $0.09 *$ & 0.05 & $-0.15 * * *$ & $0.06^{*}$ \\
\hline $\mathrm{HbA}_{1 \mathrm{c}}$ & $0.07 *$ & $0.06^{*}$ & 0.04 & $0.06^{*}$ & 0.05 & 0.05 & $-0.07 *$ & 0.04 \\
\hline $\mathrm{EGDR}^{\mathrm{a}}$ & $-0.10 * * *$ & $-0.10 * * *$ & $-0.08 *$ & $-0.10 * * *$ & -0.03 & $-0.08^{*}$ & $0.07 *$ & -0.01 \\
\hline AER & 0.05 & $0.06^{*}$ & -0.02 & 0.04 & 0.02 & -0.01 & -0.05 & $0.06^{*}$ \\
\hline
\end{tabular}

${ }^{a}$ EGDR was calculated according to the formula published by the Pittsburgh Epidemiology of Diabetes Complications (EDC) Study and derived from euglycaemic hyperinsulinemic clamps performed in 24 patients with type 1 diabetes (see the Methods section)

${ }^{*} p<0.05, * * * p<0.001$

CHO, carbohydrate; MUFA, monounsaturated fatty acids; PUFA, polyunsaturated fatty acids

without diabetes. Fibre intake was low among all participants, particularly men.

This study has some important limitations. The dietary intake data are self-reported, and there is the possibility of bias or misclassification, especially as patients with type 1 diabetes may be more accustomed to answering questions regarding their diet. In addition, diet questionnaires were not completed by some of the study participants and 40 diet questionnaires were excluded from the analysis because of excessively low or high reported energy intake. The 40 study participants who were excluded did not differ significantly from those included in the analysis in terms
Table 3 Univariate associations of covariates with CAC

\begin{tabular}{|c|c|c|}
\hline Covariate & Odds ratio $(95 \% \mathrm{CI})^{\mathrm{a}}$ & $p$ value \\
\hline Age (per 10 years) & $2.4(2.1-2.8)$ & $<0.0001$ \\
\hline Diabetes (yes vs no) & $1.9(1.5-2.4)$ & $<0.0001$ \\
\hline Sex (men vs women) & $3.0(2.4-3.9)$ & $<0.0001$ \\
\hline $\mathrm{HbA}_{1 \mathrm{c}}($ per $1.5 \%)$ & $1.5(1.3-1.6)$ & $<0.0001$ \\
\hline Duration (per 10 years) & $2.5(2.0-3.1)$ & $<0.0001$ \\
\hline IAF (per $\left.0.65 \mathrm{~cm}^{2}\right)$ & $2.1(1.8-2.4)$ & $<0.0001$ \\
\hline BMI (per $4.7 \mathrm{~kg} / \mathrm{m}^{2}$ ) & $1.9(1.7-2.1)$ & $<0.0001$ \\
\hline Waist circumference (per $13.6 \mathrm{~cm}$ ) & $2.5(2.1-2.8)$ & $<0.0001$ \\
\hline Cholesterol (per 38 mmol/l) & $1.3(1.1-1.4)$ & 0.0001 \\
\hline HDL-cholesterol (per 16 mmol/l) & $0.77(0.68-0.87)$ & $<0.0001$ \\
\hline Non-HDL-cholesterol (per $38 \mathrm{mmol} / \mathrm{l}$ ) & $1.4(1.2-1.6)$ & $<0.0001$ \\
\hline LDL-cholesterol (per $32 \mathrm{mmol} / \mathrm{l}$ ) & $1.3(1.1-1.4)$ & 0.0002 \\
\hline Apolipoprotein B (per 27 g/l) & $1.4(1.2-1.6)$ & $<0.0001$ \\
\hline Triacylglycerol (per $0.52 \log \mathrm{mmol} / \mathrm{l}$ ) & $1.4(1.3-1.6)$ & $<0.0001$ \\
\hline Physical activity (per $1.1 \log \mathrm{kJ} /$ week) & $0.88(0.78-0.99)$ & 0.037 \\
\hline $\mathrm{EGDR}^{\mathrm{a}}($ per 2.4$)$ & $0.42(0.36-0.48)$ & $<0.0001$ \\
\hline Daily intake (per $8.9 \mathrm{~kJ}$ day $^{-1} \mathrm{~kg}^{-1}$ ) & $0.73(0.64-0.83)$ & $<0.0001$ \\
\hline AER (per $1.3 \mu \mathrm{g} / \mathrm{min})$ & $1.6(1.4-1.8)$ & $<0.0001$ \\
\hline High-fat diet $(>35 \%$ energy as fat $)$ & $1.7(1.3-2.1)$ & $<0.0001$ \\
\hline Saturated fat (per $3.1 \%$ of daily intake) & $1.2(1.1-1.4)$ & 0.0012 \\
\hline Carbohydrate (per $9.3 \%$ of daily intake) & $0.74(0.65-0.84)$ & $<0.0001$ \\
\hline Protein (per $3.8 \%$ of daily intake) & $1.11(0.99-1.25)$ & 0.073 \\
\hline Glycaemic index (per 4.2) & $1.00(0.89-1.13)$ & 0.94 \\
\hline
\end{tabular}


Table 4 Odds ratios and 95\% CIs for association of dietary macronutrients and CAC

\begin{tabular}{|c|c|c|c|c|c|}
\hline Model & $\begin{array}{l}\text { High fat diet } \\
\text { (>35\% energy as fat) }\end{array}$ & $\begin{array}{l}\text { Saturated fat }{ }^{\mathrm{a}} \\
(\% \text { energy intake) }\end{array}$ & $\begin{array}{l}\text { Carbohydrate }{ }^{a} \\
(\% \text { energy intake) }\end{array}$ & $\begin{array}{l}\text { Protein }^{\mathrm{a}} \\
(\% \text { energy intake) }\end{array}$ & $\begin{array}{l}\text { Glycaemic } \\
\text { index }^{\text {a }}\end{array}$ \\
\hline $\begin{array}{l}\text { Model 1: Adjusted for age, sex, total } \\
\text { energy intake }(\mathrm{kJ}) \text { and diabetes }\end{array}$ & $1.34(1.03-1.76)$ & $1.16(1.01-1.33)$ & $0.84(0.73-0.97)$ & $1.20(1.04-1.37)$ & $1.03(0.90-1.19)$ \\
\hline Model $1+$ HDL cholesterol & $1.31(0.99-1.72)$ & $1.15(1.00-1.32)$ & $0.82(0.71-0.94)$ & $1.19(1.04-1.37)$ & $1.02(0.89-1.17)$ \\
\hline Model $1+$ triacylglycerol & $1.34(1.02-1.77)$ & $1.16(1.01-1.34)$ & $0.83(0.72-0.95)$ & $1.22(1.06-1.40)$ & $0.99(0.86-1.14)$ \\
\hline Model 1 + LDL-cholesterol, statin use & $1.28(0.97-1.69)$ & $1.12(0.98-1.29)$ & $0.85(0.74-0.98)$ & $1.20(1.05-1.40)$ & $1.02(0.89-1.18)$ \\
\hline Model $1+$ non-HDL-cholesterol & $1.24(0.95-1.64)$ & $1.12(0.97-1.29)$ & $0.87(0.75-0.997)$ & $1.20(1.04-1.38)$ & $1.02(0.89-1.17)$ \\
\hline Model $1+$ apolipoprotein B & $1.23(0.93-1.63)$ & $1.14(0.99-1.31)$ & $0.86(0.75-0.99)$ & $1.20(1.04-1.38)$ & $1.02(0.88-1.17)$ \\
\hline Model $1+$ hypertension & $1.28(0.97-1.68)$ & $1.14(0.995-1.31)$ & $0.85(0.74-0.98)$ & $1.20(1.05-1.39)$ & $1.01(0.88-1.17)$ \\
\hline Model 1 + BMI & $1.07(0.80-1.43)$ & $1.03(0.89-1.20)$ & $0.93(0.80-1.08)$ & $1.14(0.98-1.32)$ & $1.00(0.87-1.16)$ \\
\hline Model 1 + physical activity (kJ/week) & $1.25(0.94-1.67)$ & $1.11(0.97-1.29)$ & $0.86(0.74-0.99)$ & $1.21(1.05-1.40)$ & $0.99(0.86-1.14)$ \\
\hline Model 1 + EGDR & $1.23(0.93-1.63)$ & $1.11(0.97-1.28)$ & $0.87(0.76-1.01)$ & $1.19(1.03-1.37)$ & $1.00(0.87-1.16)$ \\
\hline Model $1+\mathrm{HbA}_{1 \mathrm{c}}$ & $1.34(1.02-1.76)$ & $1.16(1.01-1.33)$ & $0.85(0.73-0.97)$ & $1.18(1.03-1.36)$ & $1.03(0.90-1.19)$ \\
\hline Model $1+$ AER & $1.34(1.01-1.77)$ & $1.14(0.99-1.32)$ & $0.85(0.74-0.98)$ & $1.14(0.99-1.32)$ & $1.05(0.91-1.21)$ \\
\hline Model 1 + HDL-cholesterol, & $0.99(0.72-1.37)$ & $0.98(0.83-1.15)$ & $0.94(0.80-1.10)$ & $1.12(0.96-1.32)$ & $0.95(0.81-1.12)$ \\
\hline
\end{tabular}

triacylglycerol, LDL, apolipoprotein

$\mathrm{B}$, hypertension, BMI, physical

activity, $\mathrm{HbA}_{1 \mathrm{c}}$, and $\mathrm{AER}^{\mathrm{b}}$

${ }^{a}$ Odds ratios were calculated per standard deviation change as follows: $\mathrm{SD}$ saturated fat $\%$ intake $=3.06$; $\mathrm{SD}$ carbohydrate $\%$ intake $=9.3$; $\mathrm{SD}$ protein $\%$ intake $=3.9$; SD glycaemic index $=4.2$

${ }^{b}$ Full model excluded EGDR and non-HDL-cholesterol as these variables are linear combinations of $\mathrm{HbA}_{1 \mathrm{c}}$ and hypertension, and total cholesterol and HDL-cholesterol, respectively

of age, proportion of daily energy consumed as fat, carbohydrate, protein or saturated fat, CHD risk factors or distribution by sex and diabetes. An additional consideration is that $33 \%$ of controls $(232 / 696)$ in the study were the spouse or live-in partner of a patient with type 1 diabetes. Couples who live together may eat a diet that is more similar and share other lifestyle risk factors for $\mathrm{CHD}$ than individuals living independently, which may cause our study to underestimate differences in dietary habits between adults with and without type 1 diabetes.

The results from our study add to those of the SEARCH study [9], demonstrating that adolescents and adults with type 1 diabetes in the USA eat more fat and saturated fat than is recommended by the ADA and AHA, with correspondingly lower carbohydrate intake. Our results demonstrating poor dietary compliance are also consistent with reports from studies in Spain and Italy. Reported total fat and cholesterol intake was excessive among 209 adults with variable duration of type 1 diabetes ( 4 months -41 years) in Italy, although patients had lower overall energy intake as well as lower absolute intakes of carbohydrate, fat and saturated fat than the healthy controls [24]. Adherence to ADA nutritional guidelines were also found to be suboptimal among 93 adults with type 1 diabetes in the Diabetes Nutrition and Complications Trial in Spain [13].

Our results contrast with those of a study conducted in Australia which compared the diet of 56 adults with newly diagnosed type 1 diabetes with that of 47 people without diabetes; no differences were found between intakes of fat, saturated fat, carbohydrate or protein [8]. Overall, the diet among adults in Australia was lower in fat and higher in protein than in our study population, and the discrepancy with the current study could reflect cultural differences in diet, differing medical care or the recent onset of type 1

Table 5 Odds ratios and 95\% CIs for the association of dietary macronutrients and $\mathrm{CAC}$

\begin{tabular}{lcc}
\hline Characteristic & Odds ratio $(95 \% \mathrm{CI})^{\mathrm{a}}$ & $p$ value \\
\hline Age (per 10 years) & $2.75(2.25-3.37)$ & $<0.0001$ \\
Diabetes (yes vs no) & $3.02(1.97-4.65)$ & $<0.0001$ \\
Sex (male vs female) & $2.65(1.86-3.77)$ & $<0.0001$ \\
High-fat diet & $1.01(0.67-1.53)$ & 0.95 \\
Carbohydrate & $0.98(0.77-1.26)$ & 0.90 \\
(\% of daily energy) & & \\
Protein & Type 1 diabetes $\times$ & 0.04 \\
(\% of daily energy) & protein interaction & \\
Type 1 diabetes & $1.34(1.04-1.74)$ & 0.03 \\
Controls & $0.96(0.74-1.25)$ & 0.78 \\
Glycaemic index & $1.00(0.85-1.18)$ & 1.00 \\
Triacylglycerol & $1.22(1.02-1.46)$ & 0.03 \\
BMI & $1.79(1.50-2.14)$ & $<0.0001$ \\
EGDR & $0.74(0.61-0.91)$ & 0.004 \\
\hline
\end{tabular}

${ }^{a}$ Odds ratios were calculated per standard deviation change as follows: $\mathrm{SD}$ carbohydrate $\%$ intake $=9.3$; $\mathrm{SD}$ protein $\%$ intake $=3.9$; $\mathrm{SD}$ glycaemic index $=4.2 ; \mathrm{SD} \log$ triacylglycerol $=0.51 ; \mathrm{SD} \mathrm{BMI}=$ 4.62; $\mathrm{SD} \mathrm{EGDR}=2.33$ 
diabetes in the study group compared with the longstanding duration of diabetes in the present study.

In our study, higher intake of fat was associated with worse glycaemic control, higher total cholesterol and LDLcholesterol, increased adiposity and hypertension. In addition, total fat intake, saturated fat intake and GI of the diet were inversely associated with insulin sensitivity, while carbohydrate intake was positively correlated with insulin sensitivity. Our results are consistent with the improvement in insulin sensitivity reported among patients with type 1 diabetes following 3 months of a low-fat diet [25].

In addition, in this cohort dietary fat intake above the recommended level was associated with the presence of $\mathrm{CAC}$, although this association was no longer significant when adjustment was made for other known CHD risk factors, including HDL- and LDL-cholesterol, hypertension, BMI, physical activity and insulin sensitivity. This suggests that the association between higher dietary fat intake and CAC is mediated through increased lipids and other CHD risk factors, and that there is not an independent effect of fat intake on CHD development. A higher intake of protein was also associated with the presence of CAC, and this association was only attenuated by adjustment for BMI and AER, suggesting that a high-protein diet may contribute to subclinical atherosclerosis through obesity and renal disease; this would be consistent with the ADA advice that adults with type 1 diabetes who are at high risk for renal disease should limit protein intake [5]. When adjusted for other dietary variables, protein intake was significantly associated with CAC only in adults with type 1 diabetes, further supporting a role of high-protein intake in the pathophysiology of renal and cardiovascular disease in these patients. A diet higher in carbohydrate was associated with reduced odds of having CAC, even when adjusted for lipids, hypertension and physical activity, but this association was no longer significant when adjusted for BMI and EGDR. Of note, adjustment for $\mathrm{HbA}_{1 \mathrm{c}}$ did not attenuate the associations between a high-fat diet, saturated fat, carbohydrate or protein intake and CAC, suggesting that the effects of diet are independent of glycaemic control.

Adults with type 1 diabetes are at increased risk for the development of CHD, and diet is an important modifiable risk factor for CHD. Excess intake of fat and saturated fat among adults in this study was associated with increased CHD risk factors, including higher total cholesterol and LDL-cholesterol, obesity and poorer glycaemic control. In addition, a high-fat diet was associated with the presence of CAC, a marker of subclinical atherosclerosis. Some patients with type 1 diabetes may limit their carbohydrate intake in order to achieve better glycaemic control or to avoid additional insulin dosing; however, in this study the percentage of daily energy from carbohydrate correlated negatively with $\mathrm{HbA}_{1 \mathrm{c}}$. These results suggest that patients with type 1 diabetes may benefit from additional dietary counselling to enable them to improve their adherence to dietary guidelines in order to improve long-term cardiovascular outcomes while also addressing the need for achieving adequate glycaemic control.

Acknowledgements Support for this study was provided by the National Institutes of Health National Heart, Lung and Blood Institute grants R01 HL61753 and R01 HL079611, American Diabetes Association grant 7-06-CVD-28, and Diabetes Endocrinology Research Center Clinical Investigation Core P30 DK57516. The study was performed at the Adult General Clinical Research Center at the University of Colorado Denver Anschutz Medical Center supported by the NIH M01 RR000051, at the Barbara Davis Center for Childhood Diabetes in Denver and at Colorado Heart Imaging Center in Denver, CO, USA.

Duality of interest The authors declare that there is no duality of interest associated with this manuscript.

\section{References}

1. Rosamond W, Flegal K, Friday G et al (2007) Heart disease and stroke statistics - 2007 update: a report from the American Heart Association Statistics Committee and Stroke Statistics Subcommittee. Circulation 115:e69-e171

2. Krolewski AS, Kosinski EJ, Warram JH et al (1987) Magnitude and determinants of coronary artery disease in juvenile-onset, insulin-dependent diabetes mellitus. Am J Cardiol 59:750-755

3. Laing SP, Swerdlow AJ, Slater SD et al (2003) Mortality from heart disease in a cohort of 23,000 patients with insulin-treated diabetes. Diabetologia 46:760-765

4. Lichtenstein AH, Appel LJ, Brands M et al (2006) Diet and lifestyle recommendations revision 2006: a scientific statement from the American Heart Association Nutrition Committee. Circulation 114:82-96

5. American Diabetes Association (2006) Standards of medical care in diabetes-2006. Diabetes Care 29(Suppl 1):S4-S42

6. Yates AA, Schlicker SA, Suitor CW (1998) Dietary Reference Intakes: the new basis for recommendations for calcium and related nutrients, B vitamins, and choline. J Am Diet Assoc 98:699-706

7. Krauss RM, Eckel RH, Howard B et al (2000) AHA Dietary Guidelines: revision 2000: A statement for healthcare professionals from the Nutrition Committee of the American Heart Association. Circulation 102:2284-2299

8. Tahbaz F, Kreis I, Calvert D (2006) An audit of diabetes control, dietary management and quality of life in adults with type 1 diabetes mellitus, and a comparison with nondiabetic subjects. J Hum Nutr Diet 19:3-11

9. Mayer-Davis EJ, Nichols M, Liese AD et al (2006) Dietary intake among youth with diabetes: the SEARCH for Diabetes in Youth Study. J Am Diet Assoc 106:689-697

10. Margeirsdottir HD, Larsen JR, Brunborg C, Overby NC, DahlJorgensen K (2008) High prevalence of cardiovascular risk factors in children and adolescents with type 1 diabetes: a populationbased study. Diabetologia 51:554-561

11. Overby NC, Flaaten V, Veierod MB et al (2007) Children and adolescents with type 1 diabetes eat a more atherosclerosis-prone diet than healthy control subjects. Diabetologia 50:307-316

12. Lodefalk M, Aman J (2006) Food habits, energy and nutrient intake in adolescents with Type 1 diabetes mellitus. Diabet Med 23:1225-1232 
13. The Diabetes and Nutrition Study Group of the Spanish Diabetes Association (GSEDNu) (2006) Diabetes Nutrition and Complications Trial: adherence to the ADA nutritional recommendations, targets of metabolic control, and onset of diabetes complications. A 7-year, prospective, population-based, observational multicenter study. J Diabetes Complications 20:361-366

14. Berenson GS, Wattigney WA, Tracy RE et al (1992) Atherosclerosis of the aorta and coronary arteries and cardiovascular risk factors in persons aged 6 to 30 years and studied at necropsy (The Bogalusa Heart Study). Am J Cardiol 70:851-858

15. Detrano R, Guerci AD, Carr JJ et al (2008) Coronary calcium as a predictor of coronary events in four racial or ethnic groups. $\mathrm{N}$ Engl J Med 358:1336-1345

16. Shaw LJ, Raggi P, Schisterman E, Berman DS, Callister TQ (2003) Prognostic value of cardiac risk factors and coronary artery calcium screening for all-cause mortality. Radiology 228:826833

17. Wong ND, Hsu JC, Detrano RC, Diamond G, Eisenberg H, Gardin JM (2000) Coronary artery calcium evaluation by electron beam computed tomography and its relation to new cardiovascular events. Am J Cardiol 86:495-498

18. Arad Y, Spadaro LA, Goodman K et al (1996) Predictive value of electron beam computed tomography of the coronary arteries. 19-month follow-up of 1173 asymptomatic subjects. Circulation 93:1951-1953
19. Kondos GT, Hoff JA, Sevrukov A et al (2003) Electron-beam tomography coronary artery calcium and cardiac events: a 37-month follow-up of 5635 initially asymptomatic low- to intermediate-risk adults. Circulation 107:2571-2576

20. Rimm EB, Giovannucci EL, Stampfer MJ, Colditz GA, Litin LB, Willett WC (1992) Reproducibility and validity of an expanded selfadministered semiquantitative food frequency questionnaire among male health professionals. Am J Epidemiol 135:1114-1126; discussion $1127-1136$

21. Willett W (1998) Nutritional Epidemiology, 2nd edn. Oxford University Press, New York

22. Williams KV, Erbey JR, Becker D, Arslanian S, Orchard TJ (2000) Can clinical factors estimate insulin resistance in type 1 diabetes? Diabetes 49:626-632

23. Dabelea D, Kinney G, Snell-Bergeon JK et al (2003) Effect of type 1 diabetes on the gender difference in coronary artery calcification: a role for insulin resistance? The Coronary Artery Calcification in Type 1 Diabetes (CACTI) Study. Diabetes 52:2833-2839

24. Matteucci E, Passerai S, Mariotti M et al (2005) Dietary habits and nutritional biomarkers in Italian type 1 diabetes families: evidence of unhealthy diet and combined-vitamin-deficient intakes. Eur J Clin Nutr 59:114-122

25. Rosenfalck AM, Almdal T, Viggers L, Madsbad S, Hilsted J (2006) A low-fat diet improves peripheral insulin sensitivity in patients with Type 1 diabetes. Diabet Med 23:384-392 